\title{
Bradykinin Produces Pain Hypersensitivity by Potentiating Spinal Cord Glutamatergic Synaptic Transmission
}

\author{
Haibin Wang, ${ }^{1 \star}$ Tatsuro Kohno, ${ }^{1 \star}$ Fumimasa Amaya, ${ }^{1}$ Gary J. Brenner, ${ }^{1}$ Nobuko Ito, ${ }^{1}$ Andrew Allchorne, ${ }^{1}$ Ru-Rong Ji ${ }^{2}$ \\ and Clifford J. Woolf ${ }^{1}$ \\ ${ }^{1}$ Neural Plasticity Research Group, Department of Anesthesia and Critical Care, Massachusetts General Hospital and Harvard Medical School, Charlestown, \\ Massachusetts 02129, and 2Pain Research Center, Department of Anesthesia, Brigham and Women's Hospital and Harvard Medical School, Boston, \\ Massachusetts 02115
}

Bradykinin, an inflammatory mediator, sensitizes nociceptor peripheral terminals reducing pain threshold. We now show that the $\mathrm{B}_{2}$ kinin receptor is expressed in rat dorsal horn neurons and that bradykinin, a $B_{2}$-specific agonist, augments AMPA- and NMDA-induced, and primary afferent-evoked EPSCs, and increases the frequency and amplitude of miniature EPSCs in superficial dorsal horn neurons in vitro. Administration of bradykinin to the spinal cord in vivo produces, moreover, an NMDA-dependent hyperalgesia. We also demonstrate that nociceptive inputs result in the production of bradykinin in the spinal cord and that an intrathecal $\mathrm{B}_{2}$-selective antagonist suppresses behavioral manifestations of central sensitization, an activity-dependent increase in glutamatergic synaptic efficacy. Primary afferent-evoked central sensitization is, in addition, reduced in $\mathrm{B}_{2}$ receptor knock-out mice. We conclude that bradykinin is released in the spinal cord in response to nociceptor inputs and acts as a synaptic neuromodulator, potentiating glutamatergic synaptic transmission to produce pain hypersensitivity.

Key words: bradykinin; spinal cord; pain; synaptic transmission; glutamate; neuromodulator

\section{Introduction}

Acute nociceptive pain is the consequence of the activation of the peripheral terminals of high-threshold primary afferent nociceptor neurons by intense mechanical, chemical, or thermal stimuli (Julius and Basbaum, 2001). If a noxious peripheral stimulus damages tissue, however, an increase in pain sensitivity follows, with a reduction in pain threshold both at the immediate site of the injury (primary hyperalgesia) and in neighboring noninjured tissue (secondary hyperalgesia) (Woolf and Salter, 2000). Postinjury pain hypersensitivity results from changes both in the peripheral nervous system and the CNS. At the site of tissue damage, injured cells and recruited inflammatory cells release multiple inflammatory mediators including cytokines, growth factors, chemokines, prostanoids, amines, purines, protons, and kinins (Mizimura and Kumazawa, 1996; Levine and Reichling, 1999). These mediators reduce the threshold of nociceptor peripheral terminals, a phenomenon known as peripheral sensitization (Mizimura and Kumazawa, 1996; Levine and Reichling, 1999). Peripheral sensitization is the consequence of posttransla-

Received June 10, 2005; revised July 18, 2005; accepted July 18, 2005.

This work was supported by National Institutes of Health Grant NS039518 (C.J.W.). We thank Drs. Z. Y. Zhuang, D. Broom, C.-R. Lin, T. Samad, D.-H. Youn, and R. Griffin for technical assistance and advice.

*H.W. and T.K. contributed equally to this work.

Correspondence should be addressed to Dr. Clifford J. Woolf, Neural Plasticity Research Group, Department of Anesthesia and Critical Care, Massachusetts General Hospital and Harvard Medical School, Charlestown, MA 02129. E-mail: cwoolf@partners.org.

T. Kohno's present address: Division of Anesthesiology, Niigata University Graduate School of Medical and Dental Sciences, Niigata 951-8510, Japan.

DOI:10.1523/JNEUROSCI.2393-05.2005

Copyright $\odot 2005$ Society for Neuroscience $\quad$ 0270-6474/05/257986-07\$15.00/0 tional changes in transducer proteins, including the noxious heat-sensitive transient receptor potential vanilloid 1 (TRPV1) channel (Chuang et al., 2001) and TTX-resistant voltage-gated sodium channels (Gold et al., 1998). Kinin peptides, in particular bradykinin, are released from kininogen precursors at the site of tissue injury and inflammation by protease kallikreins and kininases and act on constitutively expressed $\mathrm{B}_{2}$ and injury-induced $\mathrm{B}_{1}$ G-protein-coupled receptors (GPCRs) expressed on primary sensory neuron peripheral terminals (Couture and Lindsey, 2000; Prado et al., 2002), to contribute to peripheral sensitization (Rueff and Dray, 1993; Couture et al., 2001).

Sensory inflow carried by nociceptors into the spinal cord induces an activity-dependent increase in synaptic efficacy in dorsal horn neurons, a phenomenon known as central sensitization (Woolf, 1983; Cook et al., 1987; Simone et al., 1991). Central sensitization results from alterations in the responsiveness of ionotropic NMDA and AMPA glutamate receptors, attributable both to the trafficking of intracytoplasmic receptors to the membrane and phosphorylation-mediated alterations in receptor/ion channel functional properties (Woolf and Salter, 2000) and is responsible for secondary hyperalgesia and allodynia, pain elicited in response to normally innocuous low-threshold afferent input (Torebjork et al., 1992). Multiple factors can induce central sensitization, notably glutamate acting on NMDA, mGluR (metabotropic glutamate receptor), and AMPA receptors, substance $\mathrm{P}$ on $\mathrm{NK}_{1}$ (neurokinin 1) receptors, BDNF on TrkB (tyrosine receptor kinase $\mathrm{B}$ ) receptors, and $\mathrm{PGE}_{2}$ (prostaglandin $\mathrm{E} 2$ ) on EP (prostaglandin E) receptors (Ji et al., 2003; Hartmann et al., 2004). These diverse ligand-gated ion channels, GPCRs, and receptor tyrosine kinases activate intracellular signaling pathways 
that ultimately increase glutamatergic synaptic efficacy by altering both glutamate release and responsiveness (Ji et al., 2003).

Bradykinin, although considered essentially a peripherally acting inflammatory mediator, has several effects that support a possible role in central pain transmission; intrathecal $B_{2}$ agonists induce thermal hyperalgesia and $\mathrm{B}_{2}$ antagonists reduce the second phase of the intraplantar formalin test, a model of acute inflammatory pain hypersensitivity (Chapman and Dickenson, 1992; Ferreira et al., 2002). The site, mechanism, and functional significance of these actions are not known. We have now examined whether, and how, bradykinin alters synaptic function in the spinal cord and whether this contributes to activity-dependent central sensitization.

\section{Materials and Methods}

In situ hybridization. Animals were perfused with saline followed by $4 \%$ paraformaldehyde in $0.1 \mathrm{M}$ phosphate buffer, $\mathrm{pH} 7.4\left(4^{\circ} \mathrm{C}\right)$, the L4-L5 spinal cord and dorsal root ganglion (DRG) were removed, postfixed for $2 \mathrm{~h}$, and then placed in 20\% sucrose. An 1100 bp B $\mathrm{B}_{2}$ PCR fragment was subcloned into pCRII vector (Invitrogen, Carlsbad, CA), and DIG-UTPlabeled sense or antisense cRNA probes were generated using T7 RNA polymerase. Sections $(10 \mu \mathrm{m})$ were acetylated $(0.25 \%$ acetic anhydride, $10 \mathrm{~min}$ ), prehybridized for $1 \mathrm{~h}$ at room temperature, incubated in hybridization buffer overnight at $55^{\circ} \mathrm{C}$, washed in $\operatorname{SSC}(5,0.2$, and $0.1 \times)$, blocked with $2 \%$ goat serum, and incubated at $4^{\circ} \mathrm{C}$ with alkaline phosphatase (1:1000; for enzymatic reaction) or peroxidase [1:50; for tyramide signal amplification (TSA) reaction] conjugated anti-DIG antibodies (Roche Diagnostics, Indianapolis, IN). Sections were visualized using $75 \mu \mathrm{g} / \mathrm{ml}$ nitroblue-tetrazolium and $50 \mu \mathrm{g} / \mathrm{ml} \mathrm{5-bromo-4-chlor-}$ indolyl-phosphate or the TSA biotin system (PerkinElmer, Wellesley, MA).

Immunohistochemistry and cell counting. After visualization of TSA signals, sections were incubated with monoclonal anti-neurofilament 200 (NF200) (1:500; Sigma, St. Louis, MO), anti-peripherin (1:100; Chemicon, Temecula, CA), anti-GFAP (1:1000; Chemicon), antiNMDA receptor subunit $\mathrm{NR}_{1}(1: 1000$; Chemicon), and anti-mouse rhodamine (1:100, Chemicon). Images for $\mathrm{NR}_{1}-\mathrm{B}_{2}$ and $\mathrm{GFAP}-\mathrm{B}_{2}$ double staining were acquired by confocal laser-scanning microscopy (MRC 600; Bio-Rad, Hercules, CA), and all other images were acquired by fluorescence microscope with a digital camera system (Nikon, Tokyo, Japan). For profile counting, four sections, at least $100 \mu \mathrm{m}$ apart, were chosen. Profile area was measured for neurons with visible nuclei using the Scion (Frederick, MD) image software.

ELISA. Levels of bradykinin in the lumbar enlargement of the spinal cord were measured by ELISA. Animals were deeply anesthetized with isoflurane, and bilateral intraplantar capsaicin ( $20 \mu \mathrm{g}, 20 \mu \mathrm{l}$; Sigma $)$ was administrated $20 \mathrm{~min}$ before decapitation. The lumbar vertebral column was removed, and the spinal cord was extruded by injecting cold lactated Ringer's solution through a 16 gauge needle into the lumbar spinal canal. The lumbar enlargement was collected and immediately frozen on dry ice. The total procedure took $<1 \mathrm{~min}$. The tissue was weighed, homogenized in $500 \mu$ l of PBS containing a protease inhibitor mixture (Sigma), and then centrifuged for $30 \mathrm{~min}$ at $4^{\circ} \mathrm{C}$ and $10,000 \mathrm{rpm}$. The supernatant was then collected and assayed for levels of bradykinin using a competitive ELISA kit (Bachem, Bubendorf, Switzerland). Duplicates of both samples and standards were used.

Spinal cord slice preparation and whole-cell patch-clamp recording. Transverse lumbar spinal cord slices $(\sim 600 \mu \mathrm{m})$ with an attached dorsal root from adult (5-8 weeks) Sprague Dawley rats (Charles River Laboratories, Wilmington, MA) were prepared with a vibrating microslicer (DTK 1500; Dosaka, Kyoto, Japan) and perfused in oxygen-bubbled Krebs' solution (in mu: $117 \mathrm{NaCl}, 3.6 \mathrm{KCl}, 2.5 \mathrm{CaCl}_{2}, 1.2 \mathrm{MgCl}_{2}, 1.2$ $\mathrm{NaH}_{2} \mathrm{PO}_{4}, 25 \mathrm{NaHCO}_{3}$, and 11.5 D-glucose) at $35^{\circ} \mathrm{C}$ for blind wholecell patch-clamp recordings. Resistance of patch pipettes were typically $4 \sim 10 \mathrm{M} \Omega$. The pipette solution contained the following (in $\mathrm{mM}$ ): $135 \mathrm{~K}$-gluconate, $0.5 \mathrm{CaCl}_{2}, 2 \mathrm{MgCl}_{2}, 5 \mathrm{KCl}, 5$ EGTA, 5 HEPES, 5 D-glucose, and 5 QX-314 (lidocaine $N$-ethyl bromide). Currents were filtered at $2 \mathrm{kHz}$ and digitized at $5 \mathrm{kHz}$ using the Axopatch 200A (Molecular Devices, Union City, CA) and analyzed by pCLAMP8.1 (Molecular Devices). Holding potential was $-70 \mathrm{mV}$ for AMPA and $-40 \mathrm{mV}$ for NMDA currents. TTX $(0.5 \mu \mathrm{M})$ was presented in the bath solution, except for recording evoked EPSCs (eEPSCs). Dorsal root stimulation, sufficient to recruit $\mathrm{A} \delta$ and $\mathrm{C}$-fiber, was delivered with a suction electrode (Kohno et al., 2003) linked to a constant-current stimulator (Digitimer, Welwyn Garden City, UK). Monosynaptic evoked EPSCs were studied in the presence of $20 \mu \mathrm{M}$ bicuculline, $2 \mu \mathrm{M}$ strychnine, and $50 \mu \mathrm{M}$ APV. Miniature EPSC (mEPSC) frequency and amplitude were analyzed with Axograph (Molecular Devices). All drugs were purchased from Sigma.

Behavior. PE-10 catheters were placed in the lumbar subarachnoid space while animals were under isoflurane anesthesia. Either Icatibant (HOE 140$)(10 / 100 \mu \mathrm{g} ; 10 \mu \mathrm{l})$ or vehicle was administrated intrathecally $20 \mathrm{~min}$ before intraplantar injections. Formalin $(1.5 \%$; $50 \mu \mathrm{l})$ was injected in the left hindpaw and time spent paw lifting and licking was counted in 5 min blocks for $60 \mathrm{~min}$. Capsaicin $(20 \mu \mathrm{g} ; 20 \mu \mathrm{l})$ was injected in the rat left heel, and mechanical sensitivity was assessed with von Frey filaments applied to the plantar surface distal to the injection site. For the hotplate test, $(+)$-5-methyl-10,11-dihydro-5H-dibenzo[a,d]cyclohepten-5,10-imine maleate (MK-801) $(0.1 \mathrm{mg} / \mathrm{kg})$ was injected intraperitoneally $15 \mathrm{~min}$ before bradykinin $(2 \mu \mathrm{g} ; 10 \mu \mathrm{l})$ intrathecal administration. Rat paw withdrawal latency was measured at $52^{\circ} \mathrm{C} . \mathrm{B}_{2}$ receptor knock-out mice were obtained from The Jackson Laboratory (Bar Harbor, ME), and capsaicin $(2.5 \mu \mathrm{g} ; 10 \mu \mathrm{l})$ was injected into the heel on one side. Mechanical sensitivity was compared before and $25 \mathrm{~min}$ after capsaicin injection. The observer was always blind to the treatment.

Data analysis. Data are expressed as mean \pm SEM. Peak AMPA and NMDA currents were measured before and after each treatment and expressed as follows: (posttreatment/pretreatment -1 ) $\times 100 \%$. Student's $t$ test, one-way ANOVA, two-way ANOVA repeated measurement followed by post hoc test [SigmaStat (Systat Software, Point Richmond, CA) and SAS (SAS Institute, Cary, NC)], and Kolmogorov-Smirnov test were used where appropriate.

\section{Results}

\section{$B_{2}$ receptor mRNA is expressed in dorsal root ganglion and dorsal horn neurons}

Although $B_{2}$ receptor protein expression is reported in DRG (Steranka et al., 1988) and dorsal horn neurons (Lopes et al., 1995), we found that the staining in these two tissues produced by three different anti- $B_{2}$ antibodies was identical in wild-type and $\mathrm{B}_{2}$ knock-out mice (data not shown). We therefore used in situ hybridization for $\mathrm{B}_{2}$ mRNA to identify the distribution and cellular localization of this receptor in adult rats. In the DRG, $B_{2}$ was expressed by both small and medium-sized sensory neurons (Fig. $1 A$ ) with a size-frequency distribution of 200-1200 $\mu \mathrm{m}^{2}$ (Fig. $1 B)$. Forty-five percent of small-diameter peripherin-positive DRG neurons with unmyelinated axons were $B_{2}$ mRNA positive, with a smaller proportion (25\%) of NF200-expressing DRG neurons with myelinated axons expressing the receptor transcript (Fig. 1C,D). In the superficial dorsal horn, $\sim 70 \%$ of NMDA $\left(\mathrm{NR}_{1}\right)$ receptor subtype immunostained neurons also expressed $\mathrm{B}_{2}$ mRNA, whereas no GFAP-positive glial cells did (Fig. 2B, C). $\mathrm{B}_{2}$ is expressed then by primary sensory and second-order dorsal horn neurons, providing an opportunity in the dorsal horn for a presynaptic and postsynaptic action of bradykinin, its endogenous ligand.

\section{Intraplantar capsaicin induces bradykinin production in spinal cord}

To test whether bradykinin is produced in the dorsal horn in response to nociceptor input, we measured bradykinin levels in the spinal cord after activation of TRPV1 receptors by intraplantar injection of capsaicin. Capsaicin was injected $(20 \mu \mathrm{g} ; 20 \mu \mathrm{l})$ in 
each hindpaw of deeply anesthetized rats. This produces a short-lasting nociceptor afferent input into the spinal cord. The lumbar enlargement of the spinal cord was rapidly removed $20 \mathrm{~min}$ after the capsaicin injection, and bradykinin levels were measured by ELISA. In the naive spinal cord, bradykinin levels were below the ELISA detection threshold $(0.03 \mathrm{ng} / \mathrm{ml})$, and this was also true for the majority of animals after intraplantar vehicle injection $(0.07 \pm$ $0.07 \mathrm{pg}$ of bradykinin per milligram of tissue; $n=7)$. Bradykinin was detectable in the spinal cord, however, after capsaicin injection $(0.37 \pm 0.07 \mathrm{pg}$ of bradykinin per milligram of tissue; $n=7$ ) (Fig. 2D). These levels are likely an underestimate, because bradykinin is broken down very rapidly (Cyr et al., 2001). Because $B_{2}$ is expressed in both presynaptic and postsynaptic elements in the dorsal horn and bradykinin, a $\mathrm{B}_{2}$-selective agonist, is induced after noxious stimulation, we next investigated whether activation of $\mathrm{B}_{2}$ by bradykinin modulates synaptic activity in the dorsal horn.

\section{Bradykinin enhances excitatory synaptic transmission in dorsal horn} Bath administration of AMPA ( $10 \mu \mathrm{M}$ for $30 \mathrm{~s}$ at $-70 \mathrm{mV})$ or NMDA $(50 \mu \mathrm{M}$ at -40 $\mathrm{mV}$ ) induced inward currents $(30-200$ pA) in lamina II neurons recorded by whole-cell patch clamp in isolated adult rat spinal cord slices. Both of these currents were potentiated ( $\sim 40 \%$ ), in $\sim 80 \%$ of the neurons tested, by preapplication for 3 min of bradykinin $(10 \mu \mathrm{M})$ with full recovery by $10 \mathrm{~min}$ (Fig. $3 A, B, D, F)$. The enhancement by bradykinin was dose dependent $(n=9)$ (Fig. $3 D)$. Pretreatment with the $\mathrm{B}_{1}$-selective agonist des-Arg ${ }^{9}$-bradykinin $(10 \mu \mathrm{M})$ did not modify either AMPA or NMDA currents (Fig. 3C,D). To confirm that the observed effect of bradykinin was mediated directly by $\mathrm{B}_{2}$ expressed on the recorded neuron, GDP- $\beta$-S, a G-protein inhibitor, was added to the pipette solution. Intrapipette GDP- $\beta$-S ( $2 \mathrm{~mm})$ blocked the potentiation by bradykinin of both AMPA $(n=5)$ and NMDA $(n=7)$ currents (Fig. $3 E, F)$. To test whether bradykinin potentiates primary afferent-evoked synaptic currents, we next examined its effects on monosynaptic AMPA receptor-mediated EPSCs (eEPSCs) evoked by stimulating $\mathrm{A} \delta$ - and C-fibers in the attached dorsal root. Both A $\delta$-fiber $(n=6)$ (Fig. $4 A-C)$ and C-fiber $(n=7)$ (Fig. $4 A, C)$ eEPSCs in superficial dorsal horn neurons were reversibly enhanced by bath application of bradykinin (Fig. 4B).

To determine whether the $\mathrm{B}_{2}$-mediated augmentation of glutamatergic transmission occurs presynaptically and/or postsynaptically, the effect of bradykinin on the frequency and amplitude of AMPA-mediated mEPSCs was measured at a $-70 \mathrm{mV}$ holding potential. The frequency (Fig. 5A-C) and amplitude (Fig. 5A-C) of mEPSCs increased ( $215 \pm 39$ and $53 \pm 9 \%$, respectively; $n=10 ; p<$ 0.001 ; paired $t$ test) after bath administration of bradykinin with a leftward shift of the interevent interval plot and a rightward shift of the cumulative amplitude plot (Fig. $5 B)(p<0.01$; KolmogorovSmirnov test). Des-Arg ${ }^{9}$-bradykinin had no detectable effect (Fig.
B

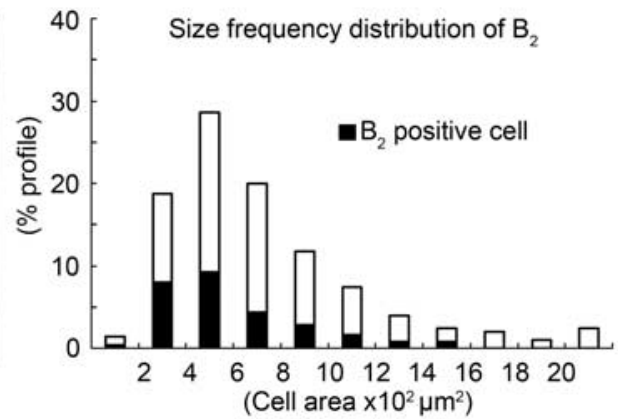

D
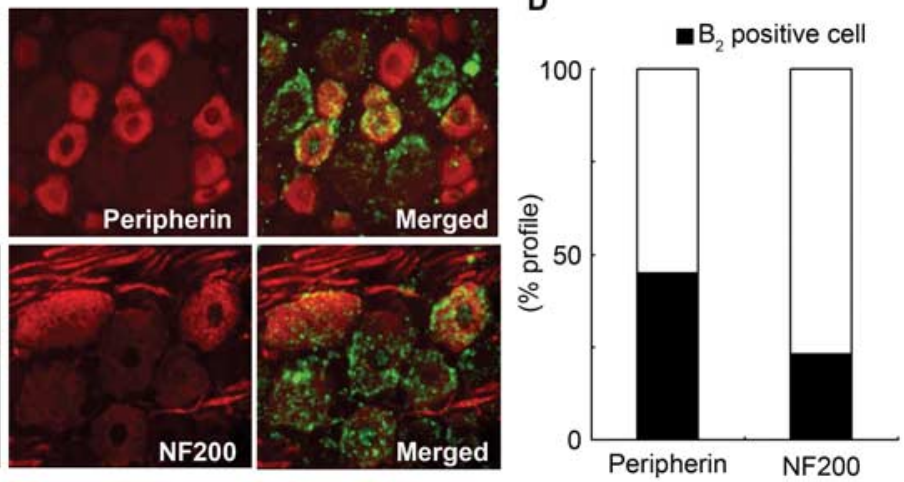

$5 A$, right). To selectively target the postsynaptic neuron and leave GPCRs on presynaptic terminals intact, we delivered GDP- $\beta$-S through the recording pipette. GDP- $\beta-\mathrm{S}(2 \mathrm{~mm} ; n=6)$ in the pipette eliminated the potentiation of the amplitude (Fig. $5 D$, right) $(p<$ 0.01 ) but not the frequency of mEPSCs by bradykinin (Fig. $5 D$, left) $(p=0.45)$. We conclude that bradykinin acts via $\mathrm{B}_{2}$ presynaptically to increase glutamate release and postsynaptically to increase the sensitivity of glutamate ionotropic receptors. This raises the question of whether this occurs in vivo and, if so, what is its functional significance?

\section{Intrathecal bradykinin causes an \\ NMDA-dependent hyperalgesia}

Intrathecal bradykinin injection ( 10 and $2 \mu \mathrm{g}$, respectively) produced mechanical (von Frey threshold, $60 \mathrm{~min}$ after treatment, $9 \pm 2.8 \mathrm{~g}$ vs control, $15.3 \pm 3 \mathrm{~g} ; n=7 ; p<0.05)$ and thermal hyperalgesia (hot plate, $52^{\circ} \mathrm{C}, n=12$ ), with a decrease in thermal response latency that peaks at $75 \mathrm{~min}$ and slowly recovers over $4 \mathrm{~h}$ (Fig. $6 A)(n=5 ; p<0.01$ vs vehicle). To test whether the bradykinin-induced pain hypersensitivity involves the NMDA receptor, rats were pretreated with the NMDA receptor antagonist MK-801 (0.1 mg/kg, i.p.) immediately before the intrathecal bradykinin injection. MK-801 pretreatment abolished the bradykinin-induced thermal hyperalgesia (Fig. 6A) $(n=6$; $p<$ 0.01 vs bradykinin only). This dose of MK-801 produced no effect on basal thermal sensitivity when given without bradykinin (Fig. 6A) $(n=6 ; p>0.05)$. Bradykinin then acts in vitro to potentiate NMDA receptor action and in vivo to produce an NMDA receptor-dependent pain hypersensitivity. 
A

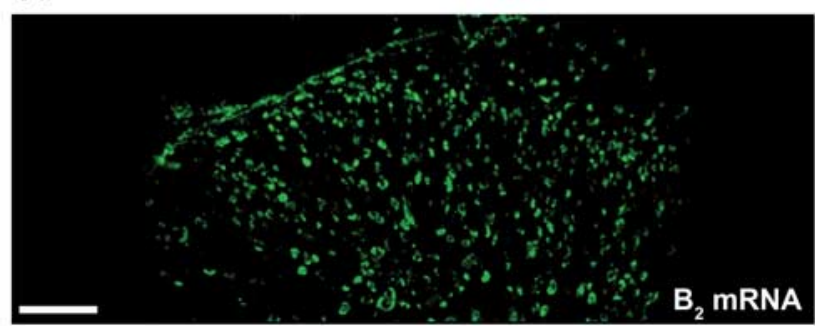

B
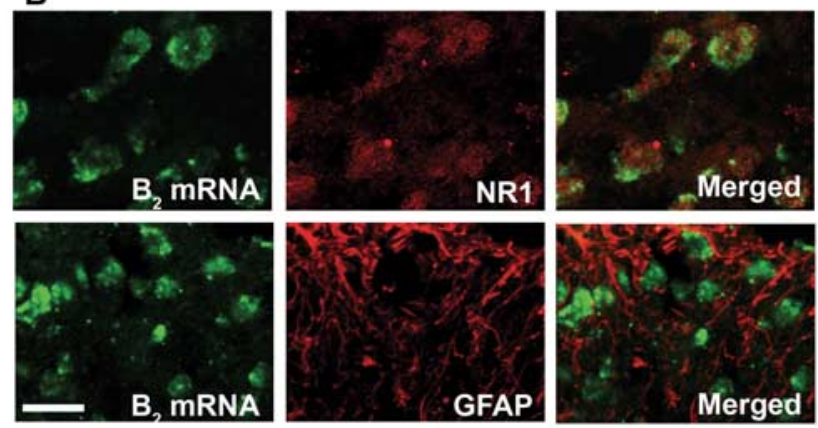

C

D
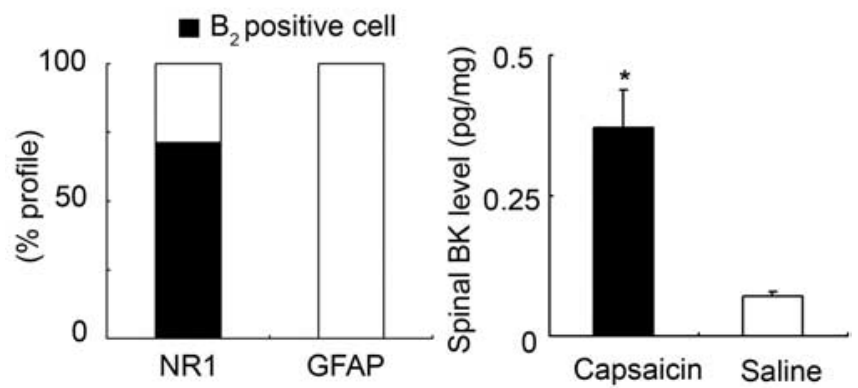

Figure 2. $\quad B_{2}$ receptor mRNA is expressed in dorsal horn neurons and not in glia. $A$, In situ hybridization reveals that $B_{2}$ mRNA is expressed throughout the dorsal horn, with high levels of expression within the superficial laminas (laminas I and II) and deep laminas (lamina IV/V). Scale bar, $50 \mu \mathrm{m}$. $\boldsymbol{B}$, In situ hybridization and immunohistochemistry double labeling shows that $B_{2}$ receptor mRNA (green) colocalizes with $N_{1}$ (neuronal marker; red, top panel) but not GFAP (glial marker; red, bottom panel) in the dorsal horn. Scale bar, $20 \mu \mathrm{m}$. C, Coexpression ratio of $B_{2}$ mRNA (filled portion of the bar) within $N_{1}$ or GFAP populations. $D$, Twenty minutes after bilateral intraplantar capsaicin injection ( $20 \mu \mathrm{g} ; 20 \mu \mathrm{l}$; filled box; $n=7)$, bradykinin (BK) levels in the lumbar enlargement of the spinal cord increased compared with vehicle controls (open box; $n=7$ ). ${ }^{*} p<0.01$. Error bars represent SEM.

\section{$A B_{2}$ antagonist blocks central sensitization}

Intraplantar injection of formalin $(1.5 \% ; 50 \mu \mathrm{l})$ induces two behavioral responses in rodents: an immediate foot lifting and paw licking that lasts $\sim 5 \mathrm{~min}$ and is attributable to the direct irritant action of formalin on nociceptors (phase 1) and a second phase that peaks at $\sim 40 \mathrm{~min}$ and reflects the action of low-level ongoing nociceptor input on a spinal cord sensitized by the earlier input (phase 2) (Fig. 6B) (Coderre and Melzack, 1992; Puig and Sorkin, 1995). The second, but not the first, phase of the formalin response is sensitive to spinal administration of NMDA receptor antagonists (Coderre and Melzack, 1992) and a conditional knock-out of the $\mathrm{NR}_{1} \mathrm{NMDA}$ receptor subunit in the dorsal horn (South et al., 2003) and is, therefore, a behavioral model of NMDA-dependent central sensitization. Intrathecal administration of $\mathrm{HOE} 140$, a $\mathrm{B}_{2}$-selective antagonist, eliminated the second phase of the formalin test, leaving the first unaffected (Fig. $6 B$ ) $(100 \mu \mathrm{g} ; n=5 ; p<0.01)$, implying that this kinin receptor
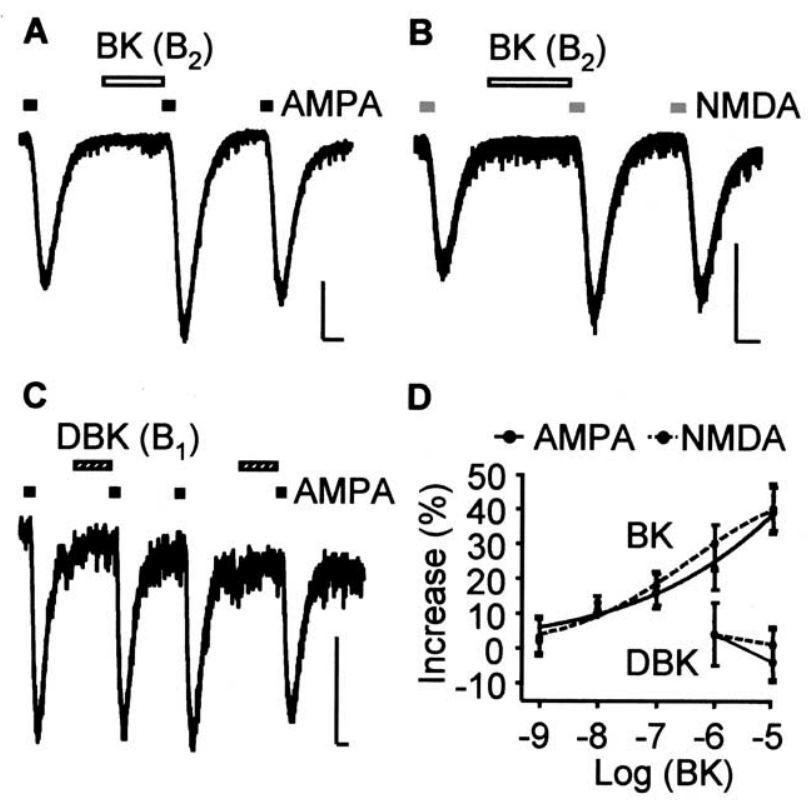

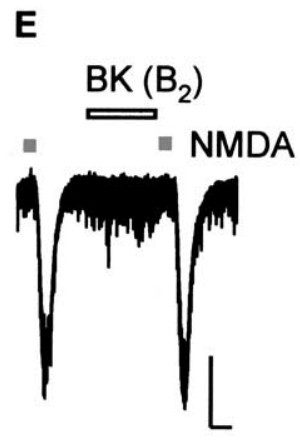

GDP- $\beta-S$ in pipette
F Vehicle BK BK+GDP- $\beta-S$

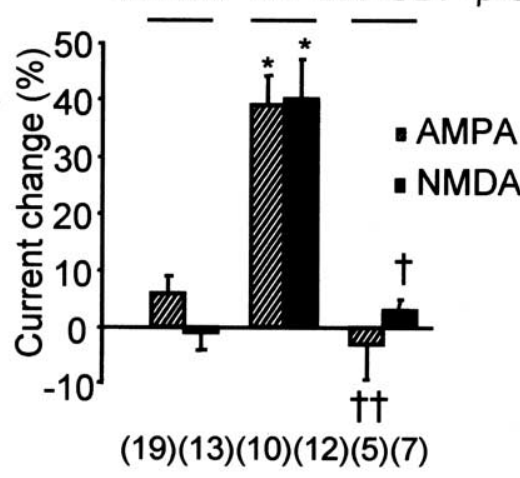

Figure 3. $A B_{2}$-selective, but not $B_{1}$-selective, agonist enhances AMPA and NMDA currents in dorsal horn neurons. $\boldsymbol{A}-\boldsymbol{C}$, Representative traces from whole-cell patch-clamped lamina II neurons indicate that bradykinin (BK), a $B_{2}$ agonist $(10 \mu \mathrm{m} ; \square)$, potentiates AMPA $(\boldsymbol{A} ; 10 \mu \mathrm{m} ; \square)$

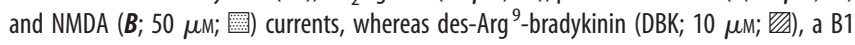
agonist, does not $(\boldsymbol{C})$. D, Dose-dependent augmentation of AMPA (solid line) and NMDA (dashed line) currents by BK but not by DBK. For each dose, $n>7$. E, A representative trace shows that the potentiation effect of bradykinin was blocked by adding GDP- $\beta$-S ( $2 \mathrm{~mm}$ ) to the pipette solution. $\boldsymbol{F}$, Cumulative data indicating that bradykinin (10 $\mu \mathrm{M})$ augments both AMPA and NMDA currents in dorsal horn neurons, and this effect is eliminated by GDP- $\beta$-S. ${ }^{*} p<$ 0.001 compared with vehicle; ${ }^{\dagger} p<0.05$ and ${ }^{\dagger \dagger} p<0.001$ compared with bradykinin (one-way ANOVA; Tukey's test). Calibration: 50 pA, 1 min. Data are means $\pm S E M$. Number of cells are indicated in parentheses.

contributes significantly to the expression of activity-dependent central sensitization.

The most characteristic feature of central sensitization is pain sensitivity to low-intensity mechanical stimuli outside the area of injury (secondary tactile allodynia) (Woolf and Salter, 2000). This can be modeled behaviorally by a subcutaneous injection of capsaicin that directly activates TRPV1-expressing nociceptors, leading to activity-dependent central sensitization and mechanical allodynia beyond the area of injection (Gilchrist et al., 1996). The mechanical hypersensitivity that manifested in the distal plantar foot after injection of capsaicin $(20 \mu \mathrm{g})$ into the proximal heel was significantly suppressed by intrathecal HOE 140 (100 $\mu \mathrm{g} ; n=8 ; p<0.05$ ) (Fig. $6 C$ ), a dose that did not itself alter basal 
A
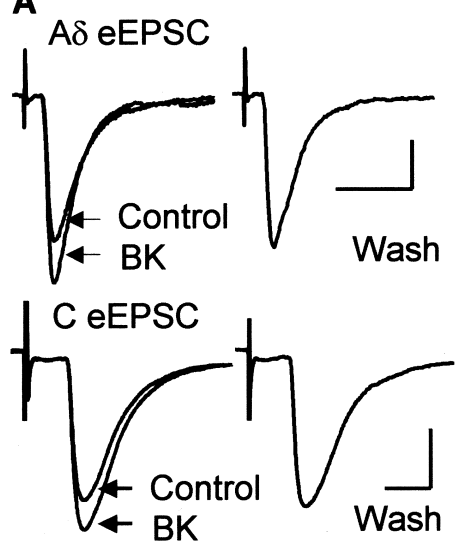

B
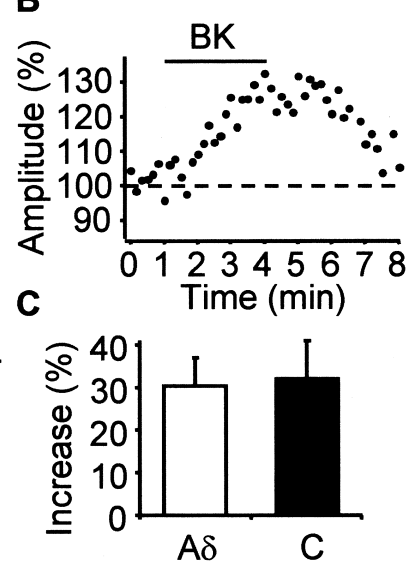

Figure 4. Potentiation by bradykinin of eEPSCs in the dorsal horn. $\boldsymbol{A}, A \delta$-and C-fiber-evoked EPSCs (average of 5 sweeps) before, during, and after application of bradykinin (BK; $10 \mu \mathrm{M}$ ). Calibration: 50 pA, $10 \mathrm{~ms}$ (A $\delta$ eEPSC); 100 pA, $20 \mathrm{~ms}$ (C eEPSC). $B$, Time course of BK-induced changes in $A \delta$-fiber eEPSCS. C, Mean enhancement of eEPSC amplitude by $B K(A \delta, n=6 ; C$, $n=7)$. Error bars represent SEM.

mechanosensitivity (Fig. 6C). Capsaicin-evoked nociceptor input induces bradykinin release in the spinal cord and $\mathrm{B}_{2}$ dependent central sensitization.

Capsaicin-induced tactile allodynia is reduced in $B_{2}$ receptor knock-out mice

To complement the pharmacological demonstration of a $\mathrm{B}_{2}$ dependent component to capsaicin-induced central sensitization, we tested whether a $B_{2}$ receptor knock-out (Rupniak et al., 1997) has a similar effect. To address this, we first investigated the immediate pain response (the first $5 \mathrm{~min}$ ) evoked by subcutaneous injection of capsaicin $(2.5 \mu \mathrm{g} ; 10 \mu \mathrm{l}) . \mathrm{B}_{2}$ receptor knock-out $(n=9)$ and wild-type $(n=6)$ mice showed no difference in this nociceptor-activated behavior (Fig. $6 D$, inset) $(p=0.4)$. This suggests that capsaicin produces a comparable level of nociceptive inputs in both the $\mathrm{B}_{2}$ receptor knock-out and wild-type mice. Basal mechanical sensitivity was also similar in both mice (Fig. 6D) $(p=1)$. However, the mechanical allodynia normally present 25 min after intraplantar capsaicin injection was significantly less in $\mathrm{B}_{2}$ receptor knock-out mice (Fig. 6D) $(p<0.05)$, indicating that these mice develop less central sensitization than wild types.

\section{Discussion}

$\mathrm{B}_{2}$ receptor activation with bradykinin augments primary afferent-evoked glutamatergic synaptic currents, the frequency and amplitude of spontaneous mEPSCs, and the currents evoked directly by AMPA and NMDA in lamina II spinal cord neurons. We conclude that bradykinin is a modulator of glutamatergic synaptic transmission in the spinal cord with presynaptic and postsynaptic actions, which is compatible with the cellular localization of $B_{2}$ receptor mRNA in small-caliber DRGs and in $\mathrm{NR}_{1}$ expressing superficial dorsal horn neurons. We did not find any $B_{2}$ receptor expression in glial cells, and the blockade by GDP- $\beta$-S of the potentiating actions of bradykinin on glutamatergic ionotropic receptors indicates a direct postsynaptic neuronal action. The more robust potentiating effect of bradykinin that we found on mEPSCs than on bath-applied AMPA/NMDA and eEPSCs may reflect a "ceiling effect" in the latter two situations in which the scope for an increase in currents is likely to be limited by the greater amount of agonist available for the binding to the recep-

A
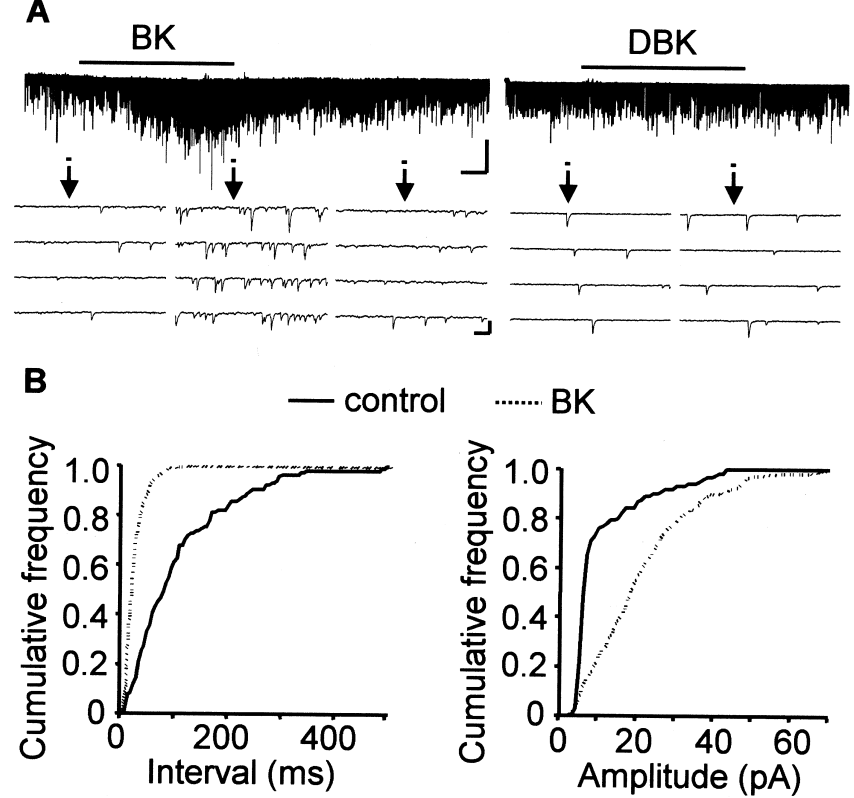

C
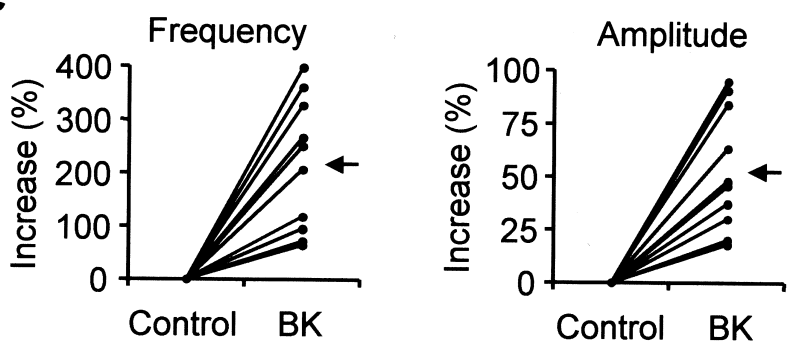

D
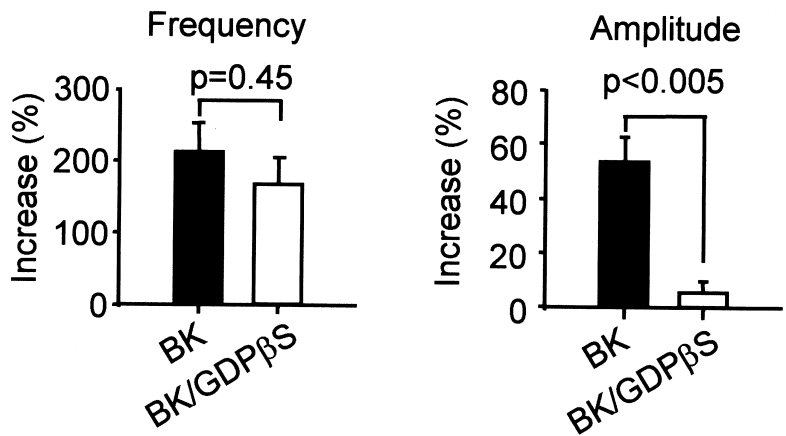

Figure 5. Potentiation by bradykinin of $m E P S C s$ in the dorsal horn suggests that both presynaptic and postsynaptic mechanisms are involved. $A$, Bradykinin (BK; $10 \mu \mathrm{m}$; left) but not des-Arg ${ }^{9}$-bradykinin (DBK; $10 \mu \mathrm{m}$; right) enhanced mEPSC frequency and amplitude. Calibration: 20 pA, 0.5 min (top); 20 pA, 50 ms (bottom). B, Cumulative distribution plots of mEPSC interevent intervals (left) and amplitudes (right). $C$, Enhancement of mEPSC frequency (left) and amplitude (right) by BK in 10 individual neurons; the arrow indicates mean. $\boldsymbol{D}$, Adding GDP- $\beta$-S ( $2 \mathrm{~mm})$ in the patch electrode eliminates BK-induced potentiation of the amplitude of mEPSCs (right; $n=6 ; p<0.005$; Student's t test) but not theirfrequency (left; $n=6 ; p=0.45$; Student's $t$ test). Data are means \pm SEM.

tors. In addition, the finding that the vesicle pools available for mEPSCs are distinct from those of eEPSCs (Sara et al., 2005) may contribute to the disparity.

The bradykinin precursor kininogen is expressed in spinal cord neurons, glia, and endothelial cells (Li et al., 1999). After administration of the kallikrein activator melittin, bradykininlike immunoreactivity becomes prominent in the dorsal horn (Lopes and Couture, 1997). We find that nociceptor afferent input increases bradykinin levels in the spinal cord from undetect- 
A

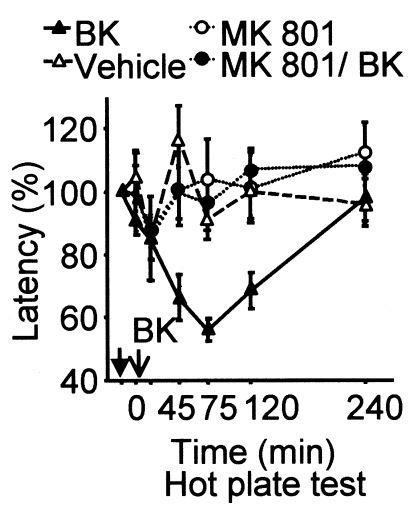

B
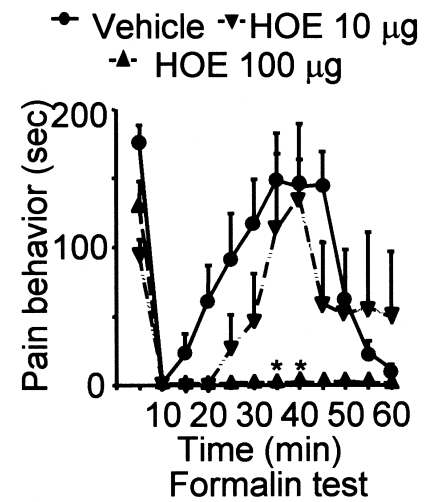

C

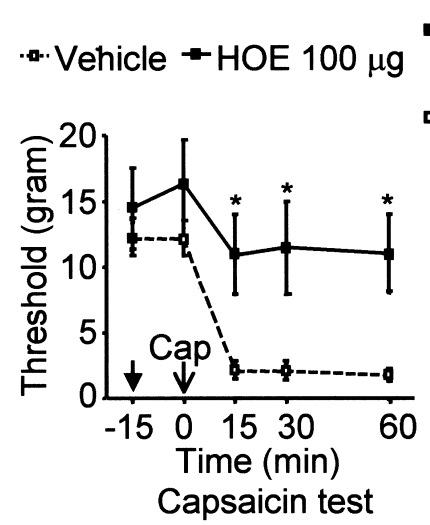

D

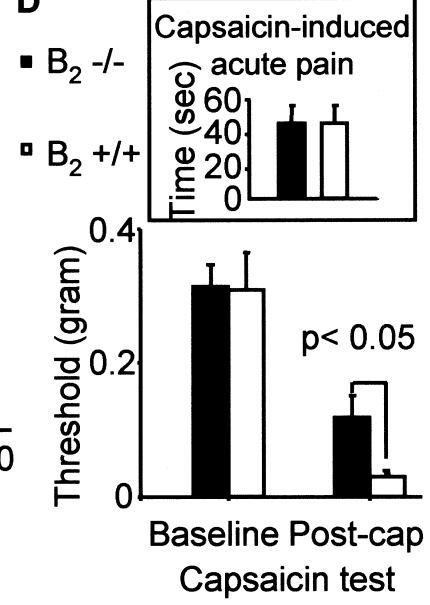

Figure 6. Bradykinin-evoked pain hypersensitivity is NMDA receptor dependent, and central sensitization is $\mathrm{B}_{2}$ receptor dependent. $\boldsymbol{A}$, Intrathecal bradykinin (BK; $2 \mu \mathrm{g} ; \mathbf{A}$ ) decreases withdrawal latency in the hotplate test $\left(52^{\circ} \mathrm{C}\right)$, and this pain hypersensitivity is attenuated by intraperitoneal pretreatment with MK-801 $(0.1 \mathrm{mg} / \mathrm{kg} ; \bigcirc)$. Neither intrathecal vehicle $(\triangle)$ nor intraperitoneal MK-801 (○) alone changes thermal sensitivity. $\boldsymbol{B}$, Effect of intrathecal administration of the $\mathrm{B}_{2}$ antagonist HOE $140(10 \mu \mathrm{g}, \boldsymbol{\nabla} ; 100 \mu \mathrm{g}, \mathbf{\Delta})$ on the first and second phase of the formalin test (vehicle; ). C, Intrathecal HOE 140 (100 $\mu \mathrm{g} ; \mathbf{\square})$ also blocks intraplantar capsaicin-induced secondary mechanical allodynia (vehicle; $\square$ ). ${ }^{*} p<0.05$. The filled arrows in $\boldsymbol{A}$ and $\boldsymbol{C}$ indicate intrathecal or intraperitoneal administration of either vehicle or treatment drugs; the open arrows indicate either BK $(\boldsymbol{A})$ or capsaicin (Cap; $\boldsymbol{C}$ ) injection. $\boldsymbol{D}$, Inset, $\mathrm{B}_{2}$ receptor knock-out mice ( $n=9 ; \square$ ) and wild-type mice $(n=6 ; \square)$ show no difference in licking/ flinching behavior for the first 5 min after subcutaneous capsaicin $(2.5 \mu \mathrm{g} ; 10 \mu \mathrm{l})$ injection. Basal mechanical sensitivity is also identical between $B_{2}$ receptor knock-out and wild-type mice, but capsaicin-induced secondary mechanical allodynia is reduced in the knock-out mice (Post-cap, $p<0.05$ ). Error bars represent SEM.

able levels in the naive state. The activity-dependent increase in bradykinin in the spinal cord represents a source of endogenous ligand for $\mathrm{B}_{2}$ receptors enabling them to modulate glutamatergic transmission in the dorsal horn. How and where nociceptor afferent inputs activate kallikrein, to convert kininogen to bradykinin, now need to be established. Is bradykinin produced in presynaptic terminals and released as a synaptic neuromodulator, is it produced in postsynaptic neurons, and does it act as an autocrine or retrograde signal, or is it produced by non-neuronal cells?

The reduction in the behavioral manifestations of activitydependent central sensitization in the spinal cord, which we find both on antagonizing the $\mathrm{B}_{2}$ receptor and in $\mathrm{B}_{2}$ null mutants, reinforces the conclusion that this kinin is a centrally acting synaptic modulator that has a particular role in producing acute

injury-induced pain hypersensitivity. Angiotensin-converting enzyme inhibitors, which are widely used to treat hypertension and cardiac failure, prevent the degradation of bradykinin because angiotensin-converting enzyme (ACE) acts on bradykinin as well as angiotensin I. This is responsible for the most prominent side effect of this class of drugs: coughing. Interestingly, another spontaneously reported side effect is pain involving any part of the body, including the chest, abdomen, limbs, joints, back, shoulder, and head (http://www.whvc.org/Treatment/ AceInhibitors.htm). No study has, however, specifically examined whether a reduction in pain threshold occurs in these patients; however, interestingly, the level of pain in human volunteers in response to sustained isometric contraction after administration of ACE inhibitors positively correlates with the concentration of bradykinin in the tested muscle (Boix et al., 2005).

What downstream signaling mechanism underlies the $B_{2}$ receptor-mediated potentiating effects on NMDA and AMPA currents in the spinal cord? The $\mathrm{B}_{2}$ receptor couples to phospholipase $C \beta$, which increases intracellular calcium and activates protein kinase $C$. The $\mathrm{B}_{2}$ receptor also couples to phospholipase $\mathrm{A}_{2}$, which converts membrane lipids to arachidonic acid that can be converted into $\mathrm{E}$ prostanoids. Additional study is required to establish the nature of the link between $\mathrm{B}_{2}$ and ionotropic glutamatergic receptors and whether it involves recruitment of the NMDA and AMPA receptors to the membrane (Carroll and Zukin, 2002) or phosphorylation-dependent changes in channel kinetics (Yu et al., 1997; Esteban et al., 2003). The major form of therapy targeted at acute central sensitization clinically has been NMDA receptor antagonists. These antagonists are certainly effective in reducing central sensitization-mediated pain in laboratory animals (Woolf and Thompson, 1991), but their use in patients is severely limited by their psychotomimetic side effects (Stubhaug et al., 1997). A better target, based on our present findings, may well be bradykinin, because we show that it is an initiator of both NMDA and AMPA use-dependent synaptic potentiation. Several other sensitizing agents, including substance $P$ and BDNF, also play a role in central sensitization. They may act in either series with the production or action of bradykinin on $\mathrm{B}_{2}$ receptors or may share common intracellular signaling pathways, providing opportunity for cross talk and synergistic interactions. The relationships and relative contributions of the different sensitizing agents will need to be worked out, but bradykinin is likely to play a prominent role.

The dual actions of bradykinin, producing peripheral sensitization in the peripheral nervous system and central sensitization in the CNS, imply that preventing its production (using kallikrein inhibitors) or action (with $\mathrm{B}_{2}$ receptor antagonists) will provide a particularly useful means of controlling acute inflammatory pain hypersensitivity.

\section{References}

Boix F, Roe C, Rosenborg L, Knardahl S (2005) Kinin peptides in human trapezius muscle during sustained isometric contraction and their relation to pain. J Appl Physiol 98:534-540.

Carroll RC, Zukin RS (2002) NMDA-receptor trafficking and targeting: implications for synaptic transmission and plasticity. Trends Neurosci 25:571-577.

Chapman V, Dickenson AH (1992) The spinal and peripheral roles of bradykinin and prostaglandins in nociceptive processing in the rat. Eur J Pharmacol 219:427-433.

Chuang HH, Prescott ED, Kong H, Shields S, Jordt SE, Basbaum AI, Chao MV, Julius D (2001) Bradykinin and nerve growth factor release the capsaicin receptor from PtdIns(4,5)P2-mediated inhibition. Nature 411:957-962. 
Coderre TJ, Melzack R (1992) The contribution of excitatory amino acids to central sensitization and persistent nociception after formalin-induced tissue injury. J Neurosci 12:3665-3670.

Cook AJ, Woolf CJ, Wall PD, McMahon SB (1987) Dynamic receptive field plasticity in rat spinal cord dorsal horn following $\mathrm{C}$ primary afferent input. Nature 325:151-153.

Couture R, Lindsey CJ (2000) Brain kallikrein-kinin system: from receptors to neuronal pathways and physiological functions. In: Handbook of chemical neuroanatomy, Vol 16, Peptide receptors Part I (Quirion R, Björklund A, Hökfelt T, eds), pp 241-300. New York: Elsevier Science.

Couture R, Harrisson M, Vianna RM, Cloutier F (2001) Kinin receptors in pain and inflammation. Eur J Pharmacol 429:161-176.

Cyr M, Lepage Y, Blais Jr C, Gervais N, Cugno M, Rouleau JL, Adam A (2001) Bradykinin and des-Arg(9)-bradykinin metabolic pathways and kinetics of activation of human plasma. Am J Physiol Heart Circ Physiol 281:H275-H283.

Esteban JA, Shi SH, Wilson C, Nuriya M, Huganir RL, Malinow R (2003) PKA phosphorylation of AMPA receptor subunits controls synaptic trafficking underlying plasticity. Nat Neurosci 6:136-143.

Ferreira J, Campos MM, Araujo R, Bader M, Pesquero JB, Calixto JB (2002) The use of kinin $\mathrm{B}(1)$ and $\mathrm{B}(2)$ receptor knockout mice and selective antagonists to characterize the nociceptive responses caused by kinins at the spinal level. Neuropharmacol 43:1188-1197.

Gilchrist HD, Allard BL, Simone DA (1996) Enhanced withdrawal responses to heat and mechanical stimuli following intraplantar injection of capsaicin in rats. Pain 67:179-188.

Gold MS, Levine JD, Correa AM (1998) Modulation of TTX-R INa by PKC and PKA and their role in PGE2-induced sensitization of rat sensory neurons in vitro. J Neurosci 18:10345-10355.

Hartmann B, Ahmadi S, Heppenstall PA, Lewin GR, Schott C, Borchardt T, Seeburg PH, Zeilhofer HU, Sprengel R, Kuner R (2004) The AMPA receptor subunits GluR-A and GluR-B reciprocally modulate spinal synaptic plasticity and inflammatory pain. Neuron 44:637-650.

Ji RR, Kohno T, Moore KA, Woolf CJ (2003) Central sensitization and LTP: do pain and memory share similar mechanisms? Trends Neurosci 26:696-705.

Julius D, Basbaum AI (2001) Molecular mechanisms of nociception. Nature 413:203-210.

Kohno T, Moore KA, Baba H, Woolf CJ (2003) Peripheral nerve injury alters excitatory synaptic transmission in lamina II of the rat dorsal horn. J Physiol (Lond) 548:131-138.

Levine JD, Reichling DB (1999) Peripheral mechanisms of inflammatory pain. In: Textbook of pain (Wall PD, Melzack R, eds), pp 59-84. Edinburgh: Churchill Livingstone.

Li Z, Tyor WR, Xu J, Chao J, Hogan EL (1999) Immunohistochemical localization of kininogen in rat spinal cord and brain. Exp Neurol 159:528-537.

Lopes P, Couture R (1997) Localization of bradykinin-like immunoreactivity in the rat spinal cord: effects of capsaicin, melittin, dorsal rhizotomy and peripheral axotomy. Neuroscience 78:481-497.

Lopes P, Kar S, Chretien L, Regoli D, Quirion R, Couture R (1995) Quantitative autoradiographic localization of [125I-Tyr8] bradykinin receptor binding sites in the rat spinal cord: effects of neonatal capsaicin, norad- renergic deafferentation, dorsal rhizotomy and peripheral axotomy. Neuroscience 68:867-881.

Mizimura K, Kumazawa T (1996) Modulations of nociceptor responses by inflammatory mediators and second messengers implicated in their action-a study in canine testicular polymodal receptors. In: The polymodal receptor: a gateway to pathological pain (Kumazawa T, Kruger L, Mizimura K, eds), pp 115-142. Amsterdam: Elsevier.

Prado GN, Taylor L, Zhou X, Ricupero D, Mierke DF, Polgar P (2002) Mechanisms regulating the expression, self-maintenance, and signalingfunction of the bradykinin B2 and B1 receptors. J Cell Physiol 193:275286

Puig S, Sorkin LS (1995) Formalin-evoked activity in identified primary afferent fibers: systemic lidocaine suppresses phase-2 activity. Pain 64: 345-355.

Rueff A, Dray A (1993) Sensitization of peripheral afferent fibres in the in vitro neonatal rat spinal cord-tail by bradykinin and prostaglandins. Neuroscience 54:527-535.

Rupniak NM, Boyce S, Webb JK, Williams AR, Carlson EJ, Hill RG, Borkowski JA, Hess JF (1997) Effects of the bradykinin B1 receptor antagonist des-Arg9[leu8]bradykinin and genetic disruption of the B2 receptor on nociception in rats and mice. Pain 71:89-97.

Sara Y, Virmani T, Deak F, Liu X, Kavalali ET (2005) An isolated pool of vesicles recycles at rest and drives spontaneous neurotransmission. Neuron 45:563-573.

Simone DA, Sorkin LS, Oh U, Chung JM, Owens CM, LaMotte RH, Willis WD (1991) Neurogenic hyperalgesia: central neural correlates in responses of spinothalamic tract neurons. J Neurophysiol 66:228-246.

South S, Kohno T, Kaspar BK, Hegarty D, Vissel B, Drake CTOM, Jenab M, Sailer AW, Malkmus S, Masuyama T, Horner P, Bogulavsk J, Gage FH, Yaksh TL, Woolf CJ, Heinmann SF, Inturrisi CE (2003) A conditional deletion of the $\mathrm{NR}_{1}$ subunit of the NMDA receptor in adult spinal cord dorsal horn reduces NMDA currents and injury-induced pain. J Neurosci 23:5031-5040.

Steranka LR, Manning DC, DeHaas CJ, Ferkany JW, Borosky SA, Connor JR, Vavrek RJ, Stewart JM, Snyder SH (1988) Bradykinin as a pain mediator: receptors are localized to sensory neurons, and antagonists have analgesic actions. Proc Natl Acad Sci USA 85:3245-3249.

Stubhaug A, Breivik H, Eide PK, Kreunen M, Foss A (1997) Mapping of punctuate hyperalgesia around a surgical incision demonstrates that ketamine is a powerful suppressor of central sensitization to pain following surgery. Acta Anaesthesiol Scand 41:1124-1132.

Torebjork HE, Lundberg LER, LaMotte RH (1992) Central changes in processing of mechanoreceptor input in capsaicin-induced sensory hyperalgesia in humans. J Physiol (Lond) 448:765-780.

Woolf CJ (1983) Evidence for a central component of post-injury pain hypersensitivity. Nature 306:686-688

Woolf CJ, Salter MW (2000) Neuronal plasticity-increasing the gain in pain. Science 288:1765-1768.

Woolf CJ, Thompson SW (1991) The induction and maintenance of central sensitization is dependent on $N$-methyl-D-aspartic acid receptor activation; implications for the treatment of post-injury pain hypersensitivity states. Pain 44:293-299.

Yu XM, Askalan R, Keil GJ2, Salter MW (1997) NMDA channel regulation by channel-associated protein tyrosine kinase Src. Science 275:674-678. 